\title{
WHEN MANUFACTURING CAPABILITY EXCEEDS CONTROL CAPABILITY: THE PARADOX OF HIGH PRECISION PRODUCTS, OR IS IT POSSIBLE TO ASSEMBLE FUNCTIONAL PRODUCTS OUT OF COMPONENTS WE ARE UNABLE TO MEASURE?
}

\author{
S. Koelemeijer Chollet, M. Braun, F. Bourgeois, J. Jacot \\ Laboratoire de Production Microtechnique, Institut de Production et Robotique, \\ Ecole Polytechnique Fédérale de Lausanne, SWITZERLAND \\ Laboratoire de Production Microtechnique \\ EPFL \\ Station 17 \\ 1015 Lausanne \\ Switzerland \\ Tél : ++ 41216935997 \\ Fax : ++ 41216933891 \\ sandra.koelemeijer.epfl.ch
}

\section{F. Chautems}

MPS AG, Bonfol, Switzerland

\begin{abstract}
Sorting and mating is a very common practice in high precision manufacturing, as well in the watch industry, biomedical or automotive industry. This strategy helps to increase the assembly yield, but is costly and timeconsuming. The question is, when is it necessary to apply sorting and mating, and when can it by avoided without loss in product quality? We furthermore show in this paper that the measurement precision is often lower than that of manufacturing. New and more precise manufacturing equipment and assembly devices allow for narrower distributions, and this raises many questions: is it possible to stop sorting? how can we be sure of the quality of the components and of the products? A case study at the company MPS AG, manufacturer of miniature ball bearings, illustrates this trend. We propose another manufacturing and assembly strategies, and show what the conditions are that are necessary to permit this approach.
\end{abstract}




\section{Introduction}

Manufacturing of high precision products such as watches is a secular activity. Despite the low quality of the old manufacturing processes, manufacturers have found pragmatic solutions to reach high precision. Over the years, empiricism and intensive human labor have made this possible. Nowadays, cost becomes an important issue, and a more effective approach is necessary.

To guarantee the functionality of high precision products, particular care has to be taken with the functional dimensions of the components. Several steps in the design phase and in manufacturing have a decisive importance: tolerancing, choice of the manufacturing process, process control, assembly, and finally the functional control of the finished product.

The manufacturers of microproducts are often faced with the following problem: manufacturing processes aren't as precise as the required tolerances. In this case, the process capability is lower than 1 [1,2]. The process capability is defined as follows (Eq.1), where USL and LSL are the upper and lower limits of the tolerance interval.

$$
C_{\text {process }}=\frac{U S L-L S L}{6 \cdot \sigma_{\text {process }}}
$$

The reason is that the main kinds of production machines are used for macro and microproducts, milling machines, automatic lathes, etc. Their capability is largely sufficient for macroparts, but is no longer when the components size drops. The process is capable if the capability value is of 1 and more, but it isn't unusual to have values of 1.5 to 3 in micromachining. Sorting and mating, or selective assembly, is the pragmatic solution to this problem.

\section{State of the art}

Selective assembly has been widely used in the precision industry over the years. This consists in classifying the batches of the two parts to assemble into classes of same dimension, and to select the convenient classes to obtain a functional assembly. On the shop-floor, the width of classes is fixed empirically, often corresponding to the resolution of the available measurement equipment, and is often of $2 \mu \mathrm{m}$ in the watch making industry (Fig. 1). Bourgeois [3] has made a thorough review on the topic of selective assembly. Academic work proposes how to optimise classes, for example with equal areas, but those methods are difficult to apply on the shop-floor $[4,5,6,7,8,9]$. 

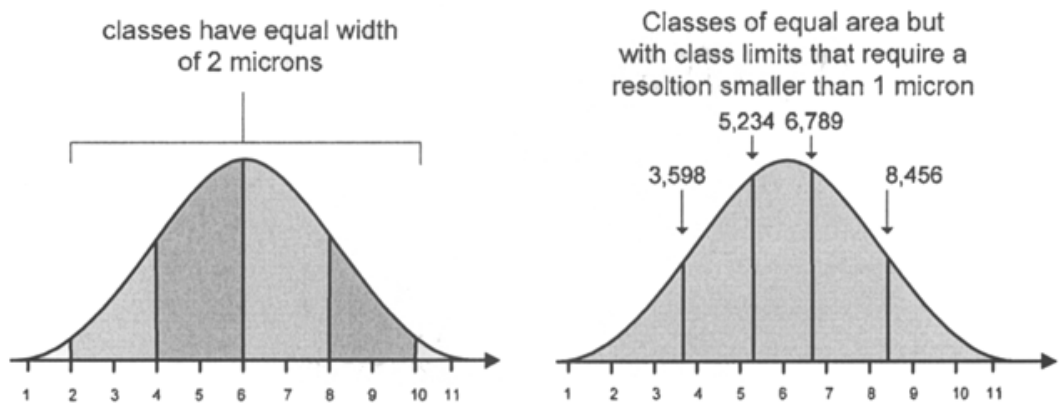

Fig. 1. Classes with equal width are commonly used in the industry, whereas classes with equal area may lead to a higher assembly yield

\section{The paradox}

The main parameters of the assembly yield - the percentage of good assemblies are the standard deviation and the off-centering of the batches to be assembled and the class width. Their effects are shown in the case study in the next paragraph. Recent developments in machine design, especially in automatic lathes, allow for narrower distributions, and thus may completely change what was considered best practice until now.

Furthermore, shop-floor people as well as academics make the same assumption: they assume that the measurement device is precise compared to the distribution of the components. Practical studies showed that a significant part of the distribution of the components is in fact due to the dispersion of the measurement (Eq. 2).

$$
\sigma_{\text {component }}^{2}=\sigma_{\text {process }}^{2}+\sigma_{\text {measurement }}^{2}
$$

We are now confronted with the following paradox: the dispersion of the machining may be tighter than that of the measurement. It is vital to redefine new strategies taking in account this paradox. How do we define classes while we are not sure we can measure the components correctly? What is the risk we take if the components aren't put in the right classes because of errors made during the measurement process?

Is it still necessary to make those classes? What is the risk we take if we don't make classes?

To answer those questions, we have to evaluate the costs related to all those cases. There is a direct cost related to measurement and sorting, as well as to production. Those costs have to be compared to the yield of the assembly, that is the number of functional parts that are manufactured. We also have to take into consideration the cost related to the risk of a non functional product arriving at the customers, and the possibility to realise a functional control at the end of the assembly process. 


\section{Case study: assembly of miniature ball bearings at MPS AG.}

MPS is one of the world leader in the manufacturing of miniature ball bearings that are mainly used in mechanical watches. The inner cage is realized in two parts (cone and noyau) which are press fitted together, at the last step of the assembly process (fig. 2). Their diameters are critical parameters of the precision of the ball bearing. If the interference is too small, the force to press fit will be low, and the ball bearing won't hold together when axial forces are applied. A too high interference will lead to the deformation of the components and the bearing won't turn smoothly.
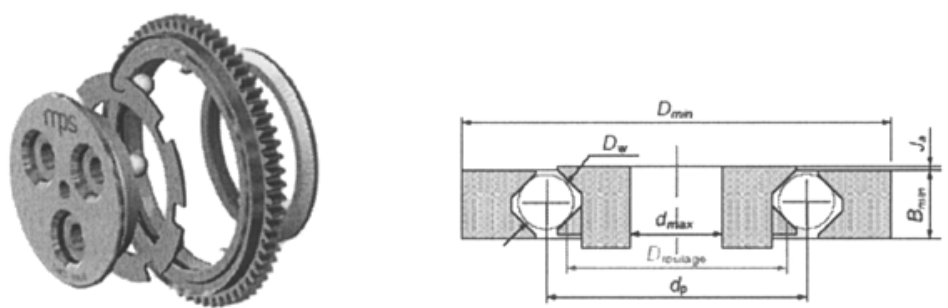

Fig. 2. Image and section off the ball-bearing - outer diameter is from 2 to $5 \mathrm{~mm}$ according variant, and balls are $300 \mu \mathrm{m}$ diameter

MPS has practised sorting and mating for years. Parts are sorted every $2 \mu \mathrm{m}$, and classes are selected to obtain a nominal interference of about 6 to $16 \mu \mathrm{m}$. Parts are press fitted with a manual press, and the functional check is done by the operator, by "feeling" the smoothness of the gliding of the balls. The sorting and mating process is expensive while very time consuming. The question about the possibility to stop this process has often been raised, but technically it has not been possible up to now. Two main technical improvements have recently been introduced: more precise automatic lathes on one hand, and a numerical press that measures the press fitting force and the $z$ position on the other hand. The question now arises again: is it possible to stop sorting [10]?

Several simulations have been run [11], in order to calculate the assembly yield with classes and without classes. Each batch is characterized by the standard deviation and the off-centering of its distribution (Fig. 3). The standard deviation is due to the capability of the manufacturing equipment. The introduction of the new lathes will lead to smaller values of the standard deviation. On the other hand, the off-centering of the batch is given by the operator when tuning the machine to manufacture a new batch. Important parameters are thus the standard deviation and the off-centering of the batch, as well as the width of the classes. 


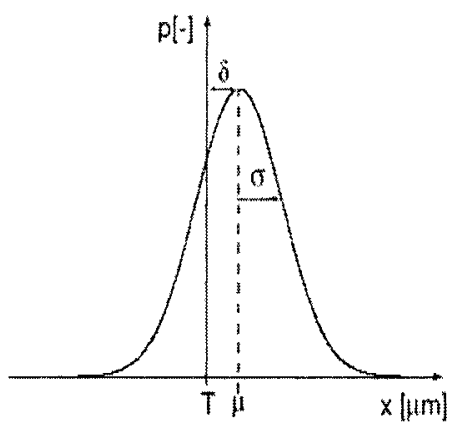

Fig. 3. Part distribution with target $\mathrm{T}$, mean $\mu$, standard deviation $\sigma$, off-centering $\delta=\mu-\mathrm{T}$

Typical parameters for the parts to be assembled are standard deviation of $2.5 \mu \mathrm{m}$ and $1.5 \mu \mathrm{m}$ with the old lathes, and of $1 \mu \mathrm{m}$ and $0.8 \mu \mathrm{m}$ with the new equipment. The assembly yield for different parameters is shown in the Table 1. One can notice that selective assembly is the most interesting with large standard deviations and rather small values of off-centering, whereas with small standard deviations, the yield isn't improved. It is thus very important to monitor the standard deviations for the different components manufactured by MPS, and the evolution due to the new equipment in order to be able to decide if sorting can be skipped.

\begin{tabular}{|c|c|c|c|c|c|}
\hline \multicolumn{6}{|l|}{ Assembly yield (\%) } \\
\hline Off-centering $(\mu \mathrm{m})$ & 0 & 1 & 2 & 3 & 4 \\
\hline & \multicolumn{5}{|c|}{ Std $2.5 \mu \mathrm{m}$ and Std $1.5 \mu \mathrm{m}$} \\
\hline Random assembly & 82,1 & 81,3 & 81,3 & 74,4 & 62,3 \\
\hline \multirow[t]{2}{*}{ Selective assembly (cw $2 \mu \mathrm{m})$} & 93,0 & 92.1 & 88,7 & 75,1 & 60,0 \\
\hline & \multicolumn{5}{|c|}{ Std $1 \mu \mathrm{m}$ and $\mathrm{Std} 0.8 \mu \mathrm{m}$} \\
\hline Random assembly & 99,1 & 96,2 & 95,8 & 79,9 & 75,4 \\
\hline Selective assembly (cw $2 \mu \mathrm{m}$ ) & 99,4 & 96,1 & 93.9 & 63,0 & 51,1 \\
\hline
\end{tabular}

Table 1. Selective assembly is particular interesting for large standard deviations and small offcenterings

In a second step, variance of the measurement device has been taken into account. The measurement device has been carefully characterized. The same batch of 10 parts has been measured 3 times by the same operator, and by 3 different operators. In the end, the measurement capability is computed and compared to the acceptable tolerance interval. This has been done for the outer diameter of the "cone" and the internal diameter of the "noyau". The variability of the total measurement system is defined as (Eq. 3):

$\sigma_{\text {measurement Error }}^{2}=\sigma_{\text {Gauge }}^{2}=\sigma_{\mathrm{Re} \text { peatability }}^{2}+\sigma_{\mathrm{Re} \text { producibility }}^{2}$ 
A system is considered acceptable with a $\mathrm{P} / \mathrm{T}$ ratio of $\mathrm{P} / \mathrm{T}<0,1$, marginally acceptable with $0,1<\mathrm{P} / \mathrm{T}<0,3$, and unacceptable with $\mathrm{P} / \mathrm{T}>0,3$. A high precision industry like the watch industry is especially prone to measurement problems. The $\mathrm{P} / \mathrm{T}$ ratio is often in the range of $\mathrm{P} / \mathrm{T}=0.5$, when measuring holes it is even mostly around $\mathrm{P} / \mathrm{T}=1$ (Eq. 4).

$$
\frac{P}{T}=\frac{6 \cdot \sigma_{\text {Gauge }}}{U S L-L S L}
$$

The values measured at MPS, with a tolerance interval USL-LSL of $8 \mu \mathrm{m}$ for both components, give $P / T$ ratio values of 0,19 and 0,39 . Those values are at the limit of what is acceptable. But if we take a tolerance interval of $2 \mu \mathrm{m}$ which is the class width, we see that the precision of the measurement is really out of scope.

The variance of the measurement process leads to the risk of misclassification of a part, either a false accept risk (risk of accepting a bad part) or a false reject risk (risk of rejecting a good part). Additional misclassifications occur with selective assembly, when putting a part in the wrong class (Fig 4).

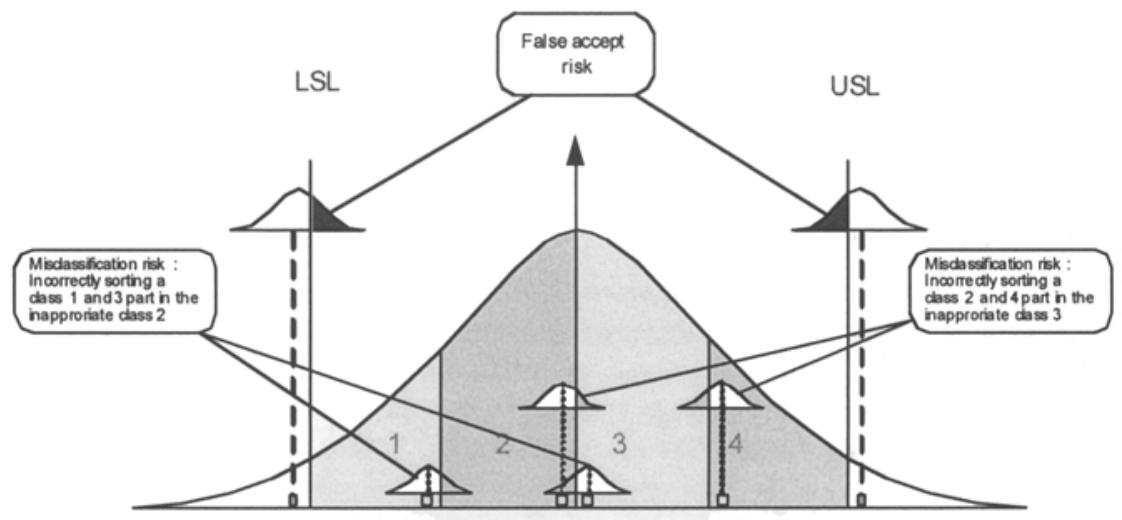

Fig. 4. The measurement error leads to general false accept risks, as well as false accept risks for each class

The values of the false accepting risk are almost negligible. The values of false rejected risk are of $3 \%$ and $5 \%$ for the internal diameter cone and the external diameter of the core with random assembly With selective assembly and classes of $2 \mu \mathrm{m}$, they are of $15 \%$ and $17 \%$.

If we now again calculate the assembly yield, the values for the selective assembly drop significantly, and are around $70 \%$ (Table 2 ). These results are very interesting for the shop-floor managers. They do corroborate their intuitive approach, as well as their first practical results. On the other hand, the number of parts rejected during the last assembly stage that controls the assembly force doesn't reach $30 \%$. This can have several meanings. Either the interference isn't as critical as generally admitted, at least not for all models of ball-bearings. Either 
other parameters such as the friction coefficient significantly affect the press fit force $[12,13]$.

The following manufacturing and assembly strategy can be suggested:

- Respect of a very narrow off-centering on both components

- Statistical dimensional control of the whole batch

- Random assembly

- Force control while press fitting

The idea is to replace the expensive $100 \%$ dimensional control on each component by a statistical dimensional control of the batch as a whole, and a $100 \%$ functional control of the assembly force during the assembly process [14].

Assembly costs are thus reduced while there is no more measuring, sorting and mating. Risks of a defect ball-bearing reaching the customers are excluded by the functional force control off the last assembly operation. This kind of manufacturing strategy is valid only if the manufacturing equipment is under control, and if the risk of a bad assembly going further into production or reaching the customer can be excluded.

\begin{tabular}{|c|c|c|c|c|c|}
\hline \multicolumn{6}{|l|}{ Assembly yield (\%) } \\
\hline Off-centering $(\mu \mathrm{m})$ & 0 & 1 & 2 & 3 & 4 \\
\hline & \multicolumn{5}{|c|}{ Std $2.5 \mu \mathrm{m}$ and Std $1.5 \mu \mathrm{m}$} \\
\hline Random assembly & 75,5 & 74,8 & 74,8 & 68,8 & 57,3 \\
\hline \multirow[t]{2}{*}{ Selective assembly (cw $2 \mu \mathrm{m}$ ) } & 67,1 & 66,9 & 66,7 & 58,1 & 47,9 \\
\hline & \multicolumn{5}{|c|}{ Std $1 \mu \mathrm{m}$ and $\operatorname{Std} 0.8 \mu \mathrm{m}$} \\
\hline Random assembly & 91,2 & 88,5 & 88,1 & 73,4 & 69,3 \\
\hline Selective assembly (cw $2 \mu \mathrm{m}$ ) & 74,5 & 72,6 & 70,5 & 51,0 & 45,0 \\
\hline
\end{tabular}

Table 2. Values of assembly yield for different class widths and standard distributions, in the case of random and selective assembly, taking in account the measurement error

\section{Further work}

Results presented in this paper are simulation results based on measurements on only two different components of one model of ball-bearing. Further measurements have to be made on a larger amount of different components, and the assembly yield predicted by the simulation has to be compared to the real assembly yield given by the assembly force. A general model for the assembly yield with the following parameters: width of classes, standard deviation, off-centering and variance of measurement device will than be proposed.

Furthermore, the functional interference leading to an acceptable range of assembly forces has to be investigated in more detail. The commonly admitted interval range may be enlarged for several ball-bearings, and the effects as well on the yield as on production control are to be analysed $[15,16,17,18]$. 


\section{References}

1. F. Bourgeois, Y. L. de Meneses, J. Jacot, "Routes \& Déroutes - Sur les traces d'un jeune ingénieur qui se lance dans la microtechnique", Revue Polytechnique, Novembre 2005

2. W. L. Pearn and P. C. Lin, "Measuring process yield based on the capability index Cpm," International Journal of Advanced Manufacturing Technology, No. 24, pp: 503-508, 2004

3. F. Bourgeois, Vers la maîtrise de la qualité des assemblages de précision, Thèse, EPFL, Ecole Polytechnique Fédérale de Lausanne, Lausanne, 2007

4. F. Bourgeois, Y. L. de Meneses, S. Koelemeijer Chollet, J. Jacot, "How much can sorting improve the capability in assembly tasks?", IEEE International Symposium on Assembly and Task Planning (ISATP03), Besançon, July 2003

5. F. Bourgeois, Y. L. de Meneses, S. Koelemeijer Chollet, J. Jacot, "De l'utilisation du tri pour augmenter le rendement d'un procédé d'assemblage", Journée d'étude de la Société Suisse de Chronométrie (SSC03), Bienne, Septembre 2003

6. Sm. Kannan, and V. Jayabalan, "A new grouping method to minimize surplus parts in selective assembly for complex assemblies," International Journal of Production Research, vol. 39, no. 9, $1851-1863,2001$

7. Sm. Kannan, A. Asha, A., and V. Jayabalan, "A New Method in Selective Assembly to Minimize Clearance Variation for a Radial Assembly Using Genetic Algorithm," Quality Engineering, Vol. 17, pp: 595-607, 2005

8. H. M. Kwon, K. J. Kim, and M. J. Chandra, "An Economic Selective Assembly Procedure for Two Mating Components with Equal Variance," Naval Research Logistics, 46: 809821,1999

9. G. A. Pugh, "Selective Assembly with Components of Dissimilar Variance," Computers and Industrial Engineering, Vol. 23, No. 1-4, pp: $487-491,1992$

10. Y. Fu, "Tolerance Analysis for Ball Bearing Assembly », Internal report, EPFL, Ecole Polytechnique Fédérale de Lausanne, Lausanne, 2007

11. M. Braun, "Optimization of the production process for high-precision ball-bearings", Internal report, EPFL, Ecole Polytechnique Fédérale de Lausanne, Lausanne, 2007

12. R. S Srinivasan, K. L. Wood, and D. A. McAdams, "Functional Tolerancing: A Design for Manufacturing Methodology," Research in Engineering Design, Vol. 2, pp. 99-115, 1996

13. F. Bourgeois, J. Jacot, "Comprendre le chassage à l'échelle horlogère", Congrès International de Chronométrie (CIC04), Montreux, Septembre 2004

14. F. Bourgeois, L. Charvier, J. Jacot, G. Genolet, H. Lorenz, "La maîtrise du procédé de chassage dans le domaine submillimétrique", Congrès International de Chronométrie (CIC07), Colombier, Septembre 2007 
15. J. Gfeller, F. Bourgeois, S. Koelemeijer Chollet, J. Jacot, "La mesure fonctionnelle: un pas décisif vers la maîtrise de la qualité", Bulletin de la Société Suisse de Chronométrie, Switzerland, Avril 2007

16. F. Bourgeois, Y. L. de Meneses, S. Koelemeijer Chollet, P-A. Adragna, M. Pillet, J. Jacot, "Tolerancing strategy for microsystem assembly", submitted to Precision Engineering the 5th of July 2006

17. J. Gfeller, S. Koelemeijer Chollet, F. Bourgeois, J. Jacot, "Functional tolerancing and testing increase microassembly yield", IEEE International Symposium on Assembly and Manufacturing (ISAM07), Michigan, July 2007

18. F. Bourgeois, Y. L. de Meneses, S. Koelemeijer Chollet, J. Jacot, "Defining assembly specifications from product functional requirements using inertial tolerancing in precision assembly", IEEE International Symposium on Assembly and Task Planning (ISATP05), Montreal, July 2005 